\title{
CERTAIN PROPERTIES OF SPIRALLIKE SAKAGUCHI TYPE FUNCTIONS CONNECTED WITH $q$-HYPERGEOMETRIC SERIES
}

\author{
Serap Bulut* ${ }^{*}$, B. Srutha KeErthi and Balakrishnan Senthil
}

Abstract. We discuss the properties like coefficient estimation, subordination results and FeketeSzegó problem for certain subclass of spirallike Sakaguchi type functions associated with $q-$ hypergeometric series.

Mathematics subject classification (2010): 30C45.

Keywords and phrases: Analytic functions, univalent functions, starlike functions, convex functions, spirallike functions, $q$-hypergeometric series, $q$-difference operator, Hadamard product, subordinating factor sequence, Fekete-Szegố problem.

\section{REFERENCES}

[1] R. J. LiberA, Univalent $\alpha$-spiral functions, Canad. J. Math., 19, (1967), 449-456.

[2] F. R. KEOGH AND E. P. MERKES, A coefficient inequality for certain classes of analytic functions, Proc. Amer. Math. Soc., 20, (1969), 8-12.

[3] L. SPACEK, Contribution a la theorie des fonctions univalents, Cas. Mat. Fys., 62, 2 (1932), $12-19$.

[4] F. H. JACKSON, On q-functions and a certain difference operator, Trans. Royal Soc. Edinburgh, 46, (1908), 253-281.

[5] A. Aral, V. Gupta And R. P. Agarwal, Applications of q-calculus in operator theory, Springer, New York, 2013.

[6] S. D. PUROHIT AND R. K. RAINA, Fractional $q$-calculus and certain subclasses of univalent analytic functions, Mathematica, 55 (78), 1 (2013), 62-74.

[7] A. MOHAMmed AND M. DARUs, A generalized operator involving the $q$-hypergeometric function, Mat. Vesnik, 65 , 4 (2013), 454-464.

[8] S. Mahmood And J. Sokol, New subclasses of analytic functions in conical domain associated with Ruscheweyh q-differential operator, Results Math., 71, (2017), 1345-1357.

[9] S. Araci, U. Duran, M. Acikgoz and H. M. Srivastava, A certain $(p, q)$-derivative operator and associated divided differences, J. Inequal. Appl., (2016) 2016:301.

[10] H. Silverman, Sufficient conditions for spiral-likeness, Internat. J. Math. Sci., 12 , 4 (1989), 641644.

[11] H. S. WILF, Subordinating factor sequence for convex maps of the unit circle, Proc. Amer. Math. Soc., 12, (1961), 689-693.

[12] H. ORhAN, D. RAducAnu, M. CAGlar And M. BAYRAM, Coefficient estimates and other properties for a class of spirallike functions associated with a differential operators, Abstr. Anal. Appl., vol. 2013, Art. ID 415319, 7 pp.

[13] H. M. Srivastava, A. K. Mishra And M. K. Das, The Fekete-Szegö problem for a subclass of close-to-convex functions, Complex Var. Theory Appl., 44, (2001), 145-163.

[14] S. KanAS AND D. RaduCANU, Some subclass of analytic functions related to conic domains, Math. Slovaca, 64, 5 (2014), 1183-1196.

[15] Z. NehaRI, Conformal mapping, McGraw-Hill, New-York, 1952.

[16] St. Ruscheweyh, New criteria for univalent functions, Proc. Amer. Math. Soc., 49, (1975), 109115 . 